\title{
U XƠ ĐÀN HỒI THỂ NHÚ Ở THẤT TRÁI KẾT HỢP BỆNH LÝ MẠCH VÀNH: NHÂN MỘT TRƯỜNG HợP
}

\author{
Nguyễn Ngọc Trung ${ }^{*}$, Nguyễn Truờng Giang ${ }^{* *}$, Vũ Đức Thắng ${ }^{*}$, Phạm Vũ Thu Hă \\ Trần Đắc Tiệp ${ }^{*}$, Nguyê̂n Chi Tuệ*, Lê Bá Hạnh", Nguyễn Thế Kiên ${ }^{*}$
}

TÓM TÁT: U tim nguyên phát là một bệnh rất hiếm gặp, chiếm khoảng 0,0017 $0,28 \%$. Trong đó, $u$ xơ đàn hồi thể nhú kết hợp với bệnh lý mạch vành cực kỳ hiếm gặp. Chúng tôi xin báo cáo một trường hợp theo dõi sau phẫu thuật 4 tháng $\mathrm{u}$ xơ đàn hồi thể nhú ở thất trái kết hợp với bệnh lý mạch vành. Bệnh nhân nữ 67 tuổi, vào viện vì đau tức ngực trái, siêu âm tim qua thành ngực và thực quản phát hiện $u$ kích thước khoảng $14 \times 18 \mathrm{~mm}$, bám xung quanh $1 / 2$ trên chân trụ cơ trước bên, mật độ âm bằng cơ tim, $\mathrm{di}$ động nhiều, hở van 2 lá và van 3 lá nhẹ, không tăng áp phổi, chức năng tâm thu thất trái trong giới hạn bình thường. Chụp động mạch vành: hẹp $40 \%$ thân chung động mạch vành, $80 \%$ động mạch liên thất trước, $90 \%$ lỗ vào động mạch mũ và $80 \%$ động mạch vành phải. Bệnh nhân được phẫu thuật tim hở bằng đường mở ngực dọc giữa xương ức, cắt $\mathrm{u}$ thất trái qua đường mở nhĩ trái qua van 2 lá, bắc 3 cầu động mạch chủ - động mạch vành. Mô bệnh học sau mổ là u xơ đàn hồi thể nhú.Sau phẫu thuật bệnh nhân ổn định, ra viện sau mổ ngày. Hiện tại 4 tháng sau mổ bệnh nhân hoàn toàn khỏe mạnh, siêu âm tim không phát hiện tái phát.

Tù khóa: U tim, u xơ đàn hồi thể nhú, bệnh lý mạch vành

\section{SUMMARY}

PAPILLARY FIBROELASTOMA OF THE LEFT VENTRICLE COMBINED WITH CORONARY ARTERY DISEASE: A CASE STUDY

Primary heart tumor is a very rare disease, accounting for about $0.0017-0.28 \%$ of all tumors. In particular, papillary fibroelasroma (PFE) combined with coronary disease (CAD)is extremely rare.We report a case of PFE of the left ventricle combined coronary artery disease. A 67year-old woman who was admitted for chest pain and her subsequent transthoracic and transesophageal echocardiography showed a mass of myocardial density, high mobility, measuring $14 \times 18 \mathrm{~mm}$ in the left ventricle, attached to the anterolateral papillary muscle. Other findings were mild mitral and tricuspid regurgitation, no pulmonary hypertension, and normal left ventricular systolic function. Coronary angiography showed stenosis of the left main (40\%),and significant stenosis of the left anterior descending artery (LAD) (80\%), left circumflex artery (LCx) $(90 \%)$ and right coronary artery (RCA) $(80 \%)$. The patient underwent a median sternotomy with cardiopulmonary bypass. The tumor was removed via the mitral valve and coronary artery bypass grafting to the LAD, LCx and RCA was performed using the left internal thoracic artery and saphenous vein grafts. The histopathology and immunohistochemistry analysis of the sample confirmed the diagnosis of PFE. Postoperative follow-up showed no sign of recurrence up to 4 months.

Keywords: Heart tumor, papillary fibroelastoma, coronary artery disease

\section{TỔNG QUAN}

U tim nguyên phát là một bệnh rất hiếm gặp, chiếm khoảng $0,0017-0,28 \%$ [1]. U tim hay gặp nhất là u nhầy, trong đó u nhầy nhĩ chiếm tỷ lệ chủ yếu. $U$ xơ đàn hồi thể nhú là loại hay gặp thứ 2 sau u nhầy [2]. U xơ nhầy thể nhú là

* Bệnh viện quân y103

** Học viện Quân $Y$

Ngườ chịu trách nhiệm khoa học: BS Nguyễn Ngọc Trung

Ngày nhận bài: 01/11/2019 - Ngày Cho Phép Đăng: 20/12/2019

Phản Biện Khoa học: PGS.TS. Đặng Ngoc Hùng GS.TS. Lê Ngoc Thành 
loại tổn thương lành tính, hình ảnh đại thể đã được các tác giả mô tả giống như con hải quỳ với nhiều xúc tu [1]. Nó có thể bám ở nội tâm mạc, tổ chức van tim, di động nhiều. Biến chứng hay gặp là tắc mạch hệ thống. Lâm sàng u xơ đàn hồi ở thất trái thường không có triệu chứng hoặc một số có biểu hiện đau ngực như bệnh lý mạch vành. Chẩn đoán hình ảnh rất dễ nhầm với u nhầy thất [3], [4], [5]. Chúng tôi xin chia sẻ về kinh nghiệm chẩn đoán và điều trị một trường hợp $\mathrm{u}$ xơ đàn hồi thể nhú trong thất trái kết hợp với bệnh lý mạch vành.

\section{CA LÂM SÀNG}

Bệnh nhân nữ 67 tuổi, thỉnh thoảng có đau tức ngực trái.Không có tiền sử bệnh lý mạn tính, không hút thuốc lá. Thăm khám lâm sàng khó thở NYHA 1, không phù, không có tiếng tim bệnh lý. Siêu âm tim qua thành ngực và siêu âm tim qua thực quản phát hiện khối u kích thước khoảng $14 \times 18 \mathrm{~mm}$, chân khối $\mathrm{u}$ bám xung quanh $1 / 2$ trên chân trụ cơ trước bên, hở van hai lá vfa van ba lá nhẹ, không tăng áp phổi, chức năng tâm thu thất trái trong giới hạn bình thường. Điện tim và xquang ngực bình thường. Chụp động mạch vành trước mổ hẹp 40\% thân chung, 80\% động mạch liên thất trước, $90 \%$ lỗ vào động mạch mũ và $80 \%$ động mạch vành phải. Về lâm sàng và chẩn đoán hình ảnh phù hợp với tổn thương dạng u nhày trong thất trái kết hợp với bệnh lý mạch vành.
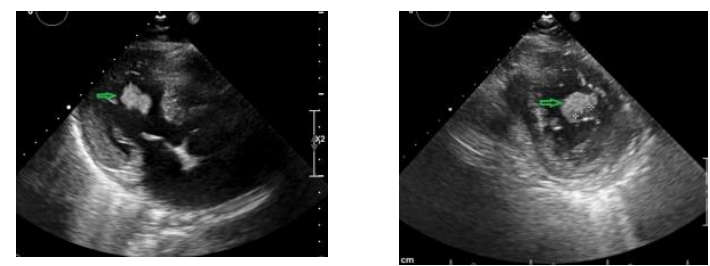

Hình 1. Hình ảnh siêu âm tim

Do đó bệnh nhân được phẫu thuật tim hở qua đường mở ngực dọc giữa xương ức. Mở nhĩ trái qua van hai lá tiếp cận khối u. Trong mổ, tổn thương u kích thước khoảng $1,5 \mathrm{~cm}$, chân nhỏ bám ào trụ cơ trước bên, hình dạng giống con hải sâm với nhiều xúc tu, di động nhiều, không xâm lấn thành thất và dây chằng, lá van hai lá. Khối u được cắt bỏ hoàn toàn bảo tồn cột cơ và dây chằng van hai lá.Sau đó, bắc ba cầu động mạch chủ - động mạch vành (01 caaud động mạch vú trong trái và 02 cầu tĩnh mạch hiển). Kết quả giải phẫu bệnh: tổn thương đại
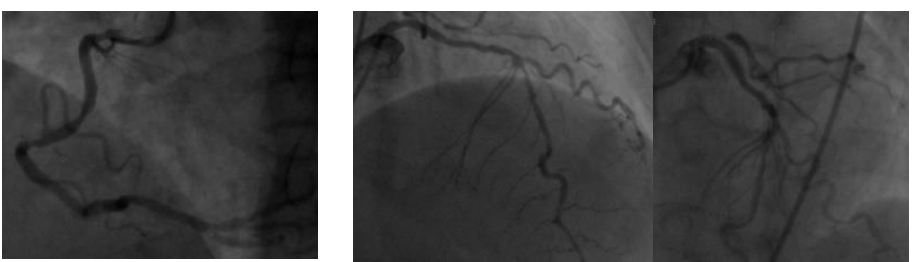

Hình 2. Hình ảnh chup động mạch vành

thể mặt cắt hơi trong, xám nhạt, nhiều tua giống xúc tu của con hải sâm. Vi thể gồm các nhú lớn nhỏ, trung tâm là lõi xơ lẫn cã sợi dạng collagen, phủ các nhú là các tế bào nội mạc tăng sinh có nhân nhỏ đều. Nhuộm hóa mô miễn dịch dương tính với $\mathrm{CD} 34, \mathrm{CD} 31$ và vimentin.Bệnh nhân được chẩn đoán $u$ xơ đàn hồi thể nhú. Sau mổ ra viện ổn định, điều trị bằng chống kết tập tiểu cầu, clopidogrel, tái khám định kỹ 1 tháng/lần. Hiện tại theo dõi sau 4 tháng phẫu thuật không phát hiện tái phát trên lâm sàng và siêu âm tim.

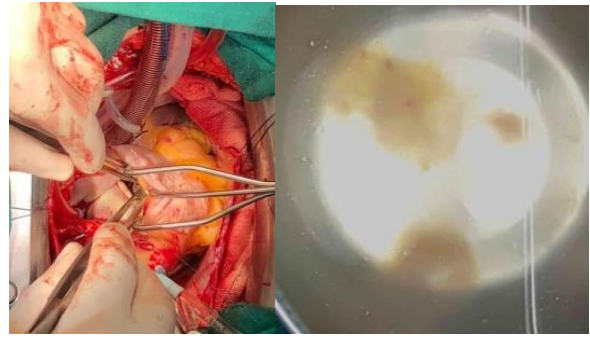

Hình 3. Hình ảnh đại thể khối u

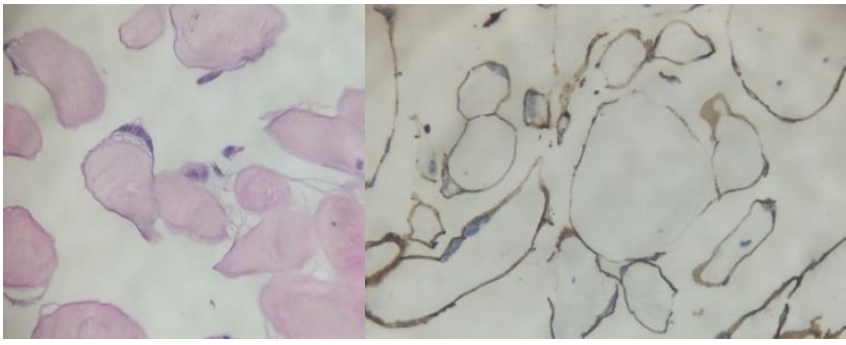

Hình 4. Hình ảnh mô bệnh học và nhuộm hóa mô miễn dịch 


\section{BÀN LUẬN}

U xơ đàn hồi thể nhú (PFE) là một khối tim lành tính hiếm gặp. Chúng có thể phát sinh từ các thành phần mô khác nhau như mô đàn hồi, mô xơ hoặc tế bào cơ trơn [1].Hình ảnh đại thể của PFE giống như con hải quỳ có nhiều nhú dạng lược và thường gắn vào van hoặc nội tâm mạc bằng một cuống hoặc chân [6].Tuy nhiên, nguồn gốc của PFE vẫn chưa được biết rõ với một số giả thuyết đã được đề cập trong y văn. Một số tác giả cho rằng chúng lá cục nghẽn của tổ chức hoặc khối có nguồn gốc do phản ứng bất thường của nội mạc bởi chấn thương huyết động hoặc nhiễm trùng [2]. Trong khi đó, một số tác giả cho rằng $\mathrm{PFE}$ có nguồn gốc tân sinh thực sự.Theo hiểu biết của chúng tôi bệnh nhân PFE kết hợp bệnh lý mạch vành thì đây là trường hợp đầu tiên được báo cáo. Phần lớn các trường hợp đã được báo cáo trong $\mathrm{y}$ văn gặp ở nữ giới tuổi từ đến tuổi. PFEs thường không có triệu chứng lâm sàng điển hình, nhưng đôi khi có thể gây ra thiếu máu cục bộ hoặc tắc mạch hệ thống, như cơn thiếu máu não thoáng qua, đột quy, đau ngực, nhồi máu cơ tim, suy tim, choáng, ngất và mù [7]. Các biến chứng đe dọa tính mạng như ngừng tim hoặc đột tử cũng đã được báo cáo. Ở bệnh nhân của chúng tôi chụp động mạch vành trước mổ ghi nhận hẹp nặng 3 thân động mạch vành. Do đó triệu chứng đau ngực khiến bệnh nhân nhập viện có thể là do biểu hiện của bệnh lý mạch vành. Tác giả Xu .H (2017) mô tả trường hợp $u$ xơ đàn hồi thể nhú ở xoang vành trái có biểu hiện đau ngực, kết hợp với chụp động mạch vành bình thường cho nên tác giả nghĩ đến triệu chứng đau ngực là bản thân bệnh u xơ đàn hồi thể nhú tạo nên. Tác giả cho rằng do khối u chèn vào lỗ mạch vành gây thiếu máu cơ tim cục bộ hoặc cũng có thể do các xúc tu của khối u chui Vào lỗ vành ở thì tâm trương gây thiếu máu cục bộ [1]. Tuy nhiên, vị trí khối u của chúng tôi không phù hợp với nhận định của Xu .H (2017). U xơ đàn hồi thể nhú có thể được chẩn đoán bằng siêu âm tim $2 \mathrm{D}$ hoặc $3 \mathrm{D}$ và siêu âm tim qua thực quản. Ngày nay, với cộng hưởng từ tim và chụp cắt lớp vi tính tim cho hình ảnh rõ nét về $\mathrm{u}$ xơ đàn hồi thể nhú ở tim [2]. Tuy nhiên, với tổn thương khối u ở trong thất trái đơn thuần phần lớn các trường hợp không có biểu hiện lâm sàng nếu như bệnh nhân không có biến chứng tắc mạch hệ thống hoặc chèn vào làm hẹp đường ra thất trái thì việc phát hiện bệnh sớm vẫn đang là một thách thức trên lâm sàng.

Phẫu thuật cắt bỏ khối u là phương pháp điều trị được chỉ định tuyệt đối ngay cả khi không có biểu hiện lâm sàng để tránh biến chứng tắc mạch [8]. Ở bệnh nhân của chúng tôi, ngoài tổn thương $\mathrm{u}$ xơ đàn hồi thể nhú trong thất trái thì hẹp nặng ba thân động mạch vành cho nên việc phẫu thuật ngoài việc điều trị tổn thương u còn bắc cầu động mạch chủ - động mạch vành là tuyệt đối. Đối với khối u trong thất trái tùy vị trí mà có ba phương pháp tiếp cận để cắt $u$ : phương pháp tiếp cận qua van động mạch chủ, phương pháp tiếp cận qua van hai lá và phương pháp tiếp cận trực tiếp qua cơ thất trái [9]. Phương pháp tiếp cận trực tiếp qua cơ thất trái đòi hỏi phải rạch vào thành thất trái, dẫn đến rối loạn chức năng thất trái sau phẫu thuật.Phương pháp tiếp cận quan van động mạch chủ thì phù hợp với những khối u nằm ở đường ra thất trái.Trong khi đó, khối u ở sau trong thất trái thì phương pháp tiếp cận qua van hai lá tỏ ra ưu việt hơn.Bệnh nhân của chúng tôi tổn thương bám vào trụ cơ trước nên chúng tôi chọn phương pháp tiếp cận qua van hai lá và chúng tôi nhận thấy đường tiếp cận này là dễ dàng để thực hiện thao tác cắt bỏ.Vấn đề ngăn chặn sự phân mảnh của khối u trong phẫu thuật lúc thực hiện thao tác cắt bỏ có thể hạn chế được biến chứng tắc mạch sau phẫu thuật.Một vấn đề cần quan tâm trong lúc phẫu thuật đối với những trường hợp khối u bám vào cơ nhú là bảo tồn tối đa cơ nhú để tránh thay van hai lá hay cắt bỏ rộng rãi rồi có thể phải thay van hai lá. Các tác giả nhận thấy rằng, về bản chất $\mathrm{u}$ xơ nhầy thể nhú là lành tính, do đó việc lấy rộng rãi tổ chức xung quanh khối u là không cần thiết. Tuy nhiên cần phải lấy hết tổ chức khối u, hạn chế tối đa tổn thương cột cơ và dây chằng.Việc cắt bỏ khối u và 
tổn thương cơ nhú buộc phải thay van hai lá cũng đã được các tác giả báo cáo [1].Ở bệnh nhân của chúng tôi kết hợp với bắc cầu động mạch chủ động mạch vành cho nên việc cắt bỏ khối u phải được tiến hành trước khi bắc cầu.

Mô bệnh học khối u sau mổ với cấu trúc u gồm các nhú lớn nhỏ, trung tâm là lõi xơ lẫn cã sợi dạng collagen, phủ các nhú là các tế bào nội mạc tăng sinh có nhân nhỏ đều.Hóa mô miễn dịch dương tính với $\mathrm{CD} 34, \mathrm{CD} 31$ và vimentin.Bệnh nhân được chẩn đoán u xơ đàn hồi thể nhú. Kết quả mô bệnh học và hóa mô miễn dịch của chúng tôi phù hợp với mô tả của các tác giả khác [5], [10].

Sau phẫu thuật bệnh nhân được điều trị bằng chống kết tập tiểu cầu và clopidogrel, theo dõi định kỳ bằng điện tim và siêu âm tim hàng tháng. Hiện tại sau 6 tháng theo dõi, bệnh nhân hoàn toàn khỏe mạnh, không đau ngực, siêu âm tim không phát hiện bệnh tái phát. Kết quả của chúng tôi phù hợp với tổn thương của $\mathrm{u}$ xơ đàn hồi thể nhú là tổn thương lành tính của tim [1], [10].

\section{KẾT LUẬA}

U xơ đàn hồi thể nhú trong thất trái kết hợp với bệnh lý mạch vành là tổn thương rất hiếm gặp. Trong những trường hợp này, phẫu thuật tim hở với cắt bỏ khối u và bắc cầu động mạch chủ động mạch vành là chỉ định tuyệt đối để đề phòng các biến cố tim mạch. Việc điều trị bằng phẫu thuật cho kết quả tốt.

\section{TÀI LIỆU THAM KHẢO}

[1] H. Xu, L. Chen, C. Ye et al., "Cardiac Papillary Fibroelastoma with Coronary Artery Anomaly: A Case Report," Heart Surg Forum, vol. 20, no. 2, pp. E052-E054, Apr 28, 2017.

[2] P. L. Chia, "Incidental finding of an aortic valve mass on 64-slice computed tomographic coronary angiography," Ann Acad Med Singapore, vol. 38, no. 10, pp. 926-7, Oct, 2009.
[3] S. Arai, D. Tanaka, M. Sakuma et al., "[Papillary Fibroelastoma of the Left Ventricular Outflow Tract;Report of a Case]," Kyobu Geka, vol. 71, no. 9, pp. 697-700, Sep, 2018.

[4] S. Page, R. Grant, and A. Iyer, "Cardiac papillary fibroelastoma originating from the left ventricular septum," J Card Surg, vol. 33, no. 4, pp. 181-182, Apr, 2018.

[5] Y. Tanaka, T. Kitamura, K. Kobayashi et al., "Papillary fibroelastoma of the left ventricular apex excised using a videoscopic technique," J Card Surg, vol. 33, no. 5, pp. 277279, May, 2018.

[6] J. M. Grinda, J. P. Couetil, S. Chauvaud et al., "Cardiac valve papillary fibroelastoma: surgical excision for revealed or potential embolization," J Thorac Cardiovasc Surg, vol. 117, no. 1, pp. 106-10, Jan, 1999.

[7] H. Kurobe, T. Kanbara, H. Yoshida et al., "Successful early resection of cardiac papillary fibroelastomas," Gen Thorac Cardiovasc Surg, vol. 59, no. 3, pp. 191-4, Mar, 2011.

[8] D. L. Ngaage, C. J. Mullany, R. C. Daly et al., "Surgical treatment of cardiac papillary fibroelastoma: a single center experience with eighty-eight patients," Ann Thorac Surg, vol. 80, no. 5, pp. 1712-8, Nov, 2005.

[9] K. Ishida, H. Satokawa, S. Takase et al., "Video-assisted endoscopic resection of left ventricular papillary fibroelastoma through the aortic valve," Asian J Endosc Surg, vol. 9, no. 4, pp. 325-327, Nov, 2016.

[10]H. Hakeem, M. Argenziano, and D. Katechis, "A Left Ventricular Papillary Fibroelastoma Presenting as an Acute Coronary Syndrome," CASE (Phila), vol. 2, no. 1, pp. 2426, Feb, 2018. 